\title{
THE RADIOLOGICAL DIAGNOSIS OF ASBESTOSIS
}

\author{
BY \\ ROGER WILLIAMS* AND P. HUGH-JONES \\ From the Department of Medicine, Postgraduate Medical School of London
}

(RECEIVED FOR PUBLICATION DECEMBER 21, 1959)

The recognition of different pneumoconioses is usually based on a history of exposure to a given dust together with the presence of characteristic changes in the chest radiograph. This implies that the radiological appearances are reasonably specific. Moreover, if they are to be used not only for clinical diagnosis but also for compensation purposes, and for the study of the disease in relation to factors such as environmental conditions or the changes in lung function, then the radiographic appearances need to be recognized and graded with little variation between different observers.

In asbestosis the changes described as being characteristic are a ground-glass mottling of the lung fields, especially in the lower parts, together with pleural thickening and a shaggy border to the heart (Fig. 1). Unfortunately no satisfactory classification of these changes has been produced and the international classification applicable to other pneumoconioses is not easily applied to asbestosis (International Labour Organization, 1959).

During an investigation into the significance of lung function changes in asbestosis (Williams and Hugh-Jones, 1960) it became necessary to try and relate the results of lung function tests to an independent assessment of the degree of change in the patient's radiograph. The study described in this paper was therefore made in order to determine not only the specificity of the radiological changes in asbestosis but to see to what extent their diagnosis and grading were affected by observer variability.

\section{DESCRIPTION OF STUdY}

A set of 53 films was chosen from the following subjects :

(1) Thirty-eight patients with asbestosis, who were the first 38 cases in the series used for lung function studies and included certified cases (21), patients who had had prolonged exposure to asbestos dust but had no symptoms and whose radiographs had previously

*Present address: Medical Unit, Royal Free Hospital, Gray's Inn Road, London, W.C.1. been regarded as clear (10), and a number who had been referred because of atypical clinical or radiological changes (7).

(2) Six normal subjects.

(3) Nine patients with other chronic respiratory diseases (four with chronic bronchitis and emphysema, three with sarcoidosis, and two with coalworkers' pneumoconiosis).

They were arranged in random order, names and identification numbers being obscured by a mask.

The films were viewed on separate occasions by two panels of observers. On the first occasion the panel of five observers (A to E) consisted of three chest physicians and one radiologist from Hammersmith Hospital together with a visiting American radiologist. Two of the physicians had had special experience in the development of similar trials in coalworkers' pneumoconiosis. On the second occasion the panel consisted of six senior medical officers of the pneumoconiosis medical panels (observers $F$ to K). The films were read "blind," the only information given to the observers being that the films were from normal subjects and from patients with asbestosis, and the other chronic pulmonary fibrosis



FIG. 1.-Classical radiological changes of asbestosis with groundglass mottling of the lung fields, shaggy border to the heart, and pleural thickening. 

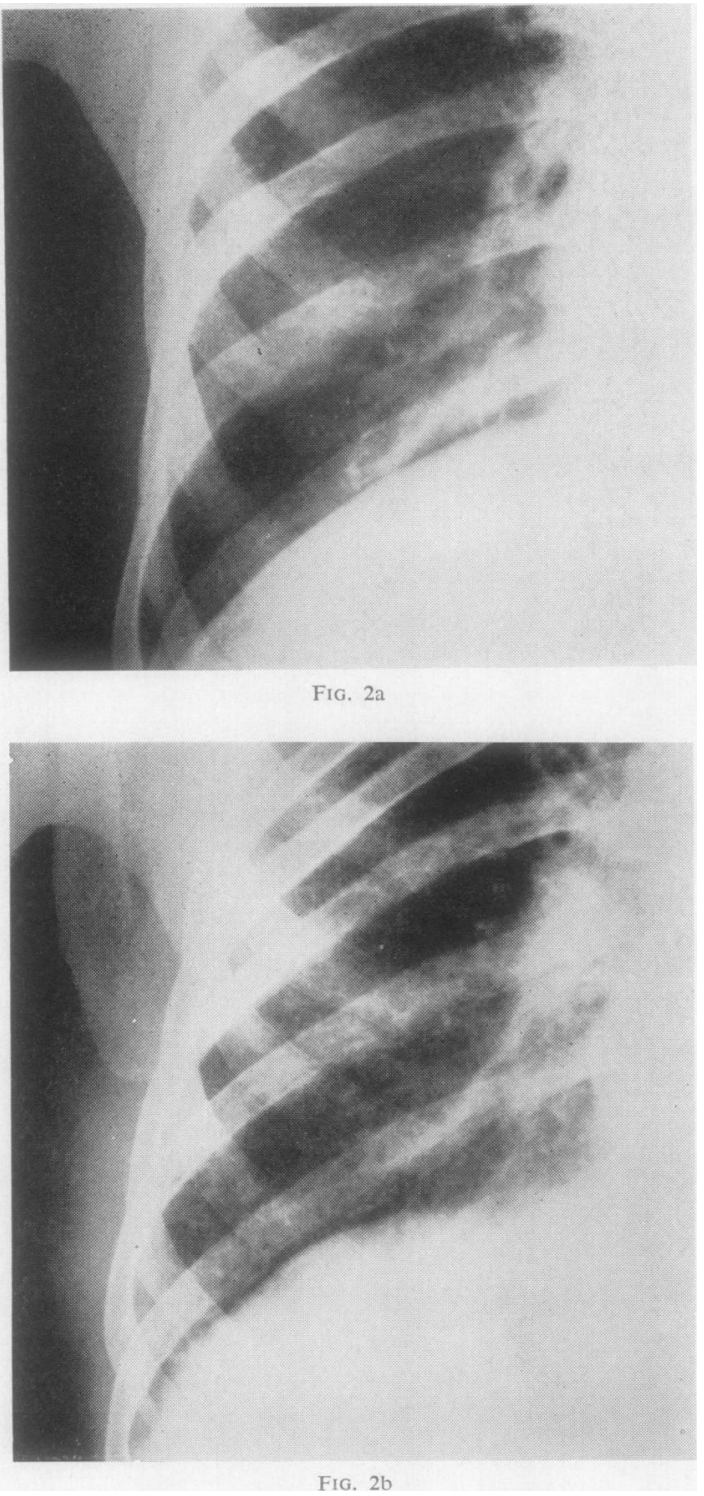

previously mentioned. Each observer recorded his answer to the following questions:

(1) Whether the film was normal.

(2) If abnormal, whether the changes seen were consistent with asbestosis or were more likely to be due to some other pulmonary fibrosis.

(3) If the film was considered to be consistent with asbestosis they were asked to record:

(a) The Severity of Mottling.-This was assessed differently on the two occasions, the first group of observers (A to $E$ ) recording it for each zone of the

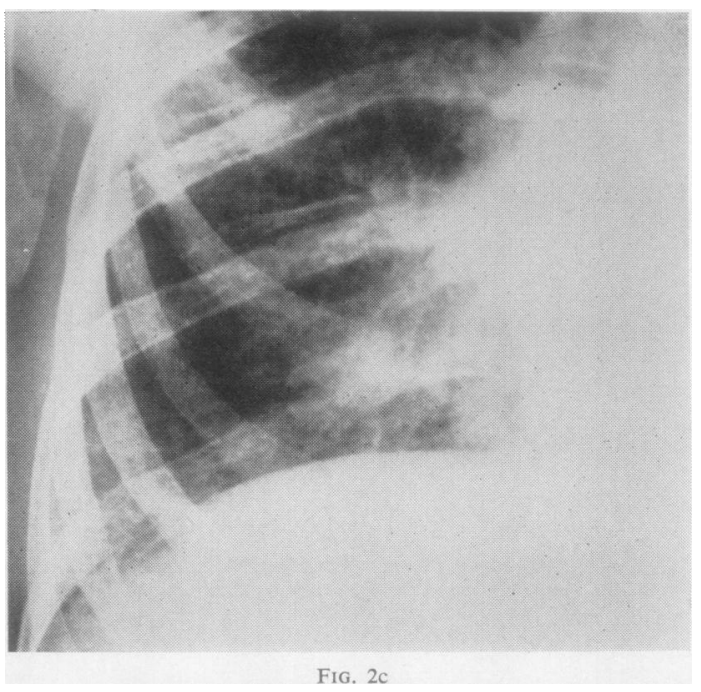

FIG. 2.-Standard films used in the grading of mottling: (a) Grade 1, (b) Grade 2, (c) Grade 3.

lung field by comparison with three standard films (Fig. 2). These had been selected so as to be representative of the range of mottling seen in asbestosis and were arbitrarily defined as slight, moderate, or $\mathbb{D}$ marked (grades 1, 2, and 3). They were in front of $\overrightarrow{\vec{B}}$ the observers throughout the trial. On the second occasion with observers $F$ to $K$ standard films were not used and the mottling was assessed purely subjectively according to the observers' experience as slight, moderate, or marked, the lung fields being considered as a whole.

(b) The Presence or Absence of (1) shaggy border ? to the heart, (2) pleural reaction, (3) bullae, these $\frac{0}{3}$ being defined as translucent areas greater than $1 \mathrm{~cm}$. in diameter.

\section{Results}

The findings of the observers are described in relation to the diagnosis of the films, then the $\frac{7}{0}$ specific changes observed in the patients with asbestosis are considered.

DiagNOSIS.- In analysing the findings the films 0 have been separated into the various groups. N

(1) Six Normal Films (Fig. 3a).-There was remarkably good agreement between the observerse in the diagnosis of these films, seven of the $\Phi$ observers being correct in all cases. One, $\stackrel{?}{+}$ however, recorded five of the six films as abnormal.

(2) Twenty-one Films from Certified Cases $\frac{\overparen{D}}{\mathbb{D}}$ of Asbestosis (Fig. 3b).-The number of films 2 thought to be consistent with asbestosis varied from 38 to $81 \%$ according to the observer. 
Although this gives some idea of the disagreement between the observers it does not show the full picture. For instance, observers $\mathrm{D}$ and $\mathrm{H}$ both recorded asbestosis in the same number of cases, yet only 10 of these 14 were the same films. In fact there were only two films in this group in which all 11 observers agreed on the presence of changes consistent with asbestosis. In Table I

TABLE I

FILMS FROM 21 CERTIFIED CASES OF ASBESTOSIS GROUPED ACCORDING TO NUMBER OF OBSERVERS AGREEING WITH DIAGNOSIS

\begin{tabular}{|c|c|}
\hline $\begin{array}{l}\text { No. of Observers Agreeing on } \\
\text { Diagnosis of Asbestosis }\end{array}$ & $\begin{array}{l}\text { No. of } \\
\text { Films }\end{array}$ \\
\hline $\begin{array}{r}11 \\
10 \\
9 \\
8 \\
7 \\
6 \\
5 \\
4 \\
3 \\
2 \\
1\end{array}$ & $\begin{array}{l}2 \\
1 \\
5 \\
2 \\
4 \\
2 \\
1 \\
1 \\
1 \\
2 \\
0\end{array}$ \\
\hline Total $\ldots$ & 21 \\
\hline
\end{tabular}

the findings have been arranged to show the level of agreement between the observers. It can be seen that if instead of complete agreement the findings of the majority of the observers, i.e., six or more, are considered, then the number of films diagnosed as asbestosis is only increased to 16 .

The wide divergence of opinion seen in many of the films in this group is illustrated by the findings in Case 17 of the main series, where two of the observers thought the film was normal, seven considered it was abnormal but showed no

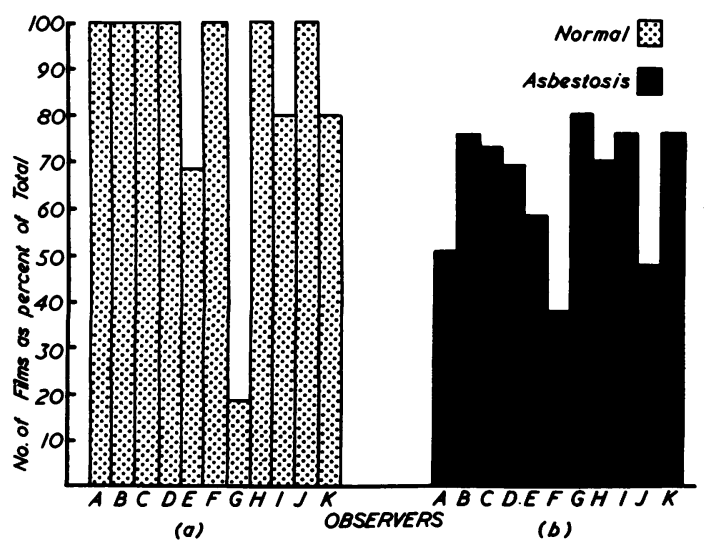

Fro. 3.-The frequency of diagnosis of $(a)$ normal films in six normal subjects, (b) asbestosis in 21 certified cases.

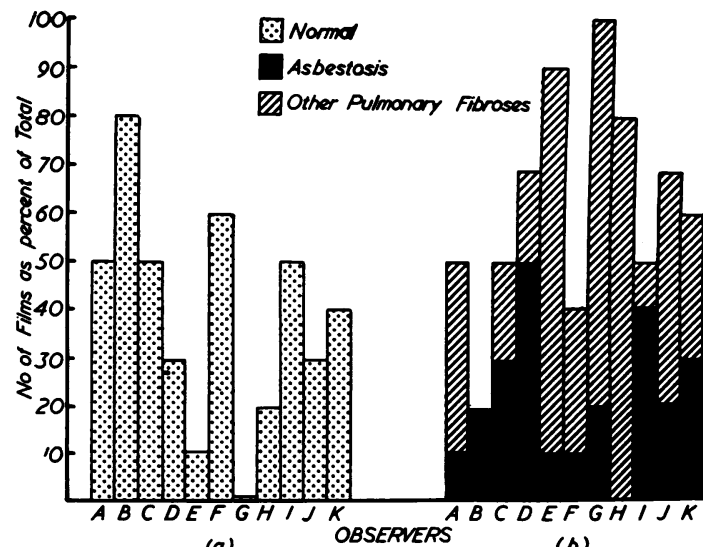

(o)

(b)

FIG. 4.-The frequency of diagnosis of $(a)$ normal films, $(b)$ asbestosis and other pulmonary diseases in 10 patients exposed to asbestos dust but whose radiograph had previously been reported as clear.

changes consistent with asbestosis, and only one agreed with the diagnosis of asbestosis previously made by the pneumoconiosis medical panel. It was of interest therefore to find that the patient did have definite functional evidence of the disease.

(3) Ten Films from Patients Exposed to Asbestos Dust but Radiologically Reported Clear (Fig. 4).-The observers differed widely in the assessment of these films, the number regarded as normal varying from 10 to $80 \%$. It might be expected that the films of some of these patients would show early changes though perhaps these might not be sufficiently marked to be regarded as abnormal. In fact the number of films thought to show changes consistent with asbestosis varied from 0 to $50 \%$. There were no films in this group in which there was complete agreement of opinion between the observers.

(4) Seven Films from Patients with Questionable Diagnosis of Asbestosis Because of Atypical Clinical or Radiological Changes (Fig. 5a).- It was to be expected that there would be particular difficulty in assessing the radiological appearances in this group. In only one case did a majority of observers agree on the presence of changes consistent with asbestosis. The majority of the films were considered to be abnormal, though there was one film which was thought to be normal by four of the 11 observers.

(5) Ten Films from Patients with Other Pulmonary Diseases (Fig. 5b).-The main point of interest in considering the findings in this group was the number of films which were thought 




FIG. 5.-The frequency of diagnosis of asbestosis in $(a)$ seven patients in whom the diagnosis had been questioned on atypical clinical or radiological findings, $(b) 10$ patients with other pulmonary diseases.

to show changes consistent with asbestosis. These varied from 0 to $60 \%$ according to the observer.

\section{The Specific Radiological Features}

MotTLING.-This will be described separately for the two groups of observers since it was assessed in a different way.

First Occasion (Observers $A$ to E).-Standard films were used and each zone of the lung field was considered separately. This was done to determine which part of the lung was mainly affected in asbestosis and whether there was a difference between the two sides. Pendergrass (1938) at one time thought that the changes began more often on the left side than on the right and progressed more on that side. The results showed that, although there was a considerable difference of opinion between the observers on the individual cases, in the majority a higher grade of mottling was recorded in the lower zones than in the mid zones. In only a few cases were grade 1 (slight) changes recorded in the upper zones and these always had moderate or marked changes in the mid and lower zones. There appeared to be little difference between the two sides. For instance, observer B, who was one of the most consistent observers, recorded in the 29 films which he considered to show mottling that it was equal in severity on the two sides in 18 . In the other 10 it was more marked on the right side in six and on the left side in five. It seemed justified, therefore, in attempting to consider the film as a whole to derive a total score for each film by adding together the grade recorded in each zone and then placing the film in one of the following categories according to the total score obtained:

\begin{tabular}{c|l}
\hline Total Score & Category \\
\hline 0 & Absent \\
$1-4$ & Slight \\
$5-8$ & Moderate \\
Over 9 & Marked \\
\hline
\end{tabular}

The frequency with which mottling was found in the 38 films of the patients who had been exposed to asbestos and number in each category are shown in Fig. 6. It is apparent that observer E not only diagnosed mottling in a greater number of cases but also placed more in the category marked. This figure does not, however, show



FIci. 6.-Frequency of diagnosis of mottling and the number in each category in 38 patients who had been exposed to asbestos dust.

the level of agreement between the observers on the individual cases. In the 36 films in which one or more of the observers recorded mottling as present there was complete agreement on the category observed in nine cases only. In the remaining 27 films the level of disagreement between the observers can be seen from Table II, where the films have been arranged according to

TABLE II

RANGE OF EXTREME OPINIONS OF OBSERVERS A-E IN 27 FILMS WITH DISAGREEMENT ON GRADE OF MOTTLING

\begin{tabular}{|c|c|c|c|c|c|}
\hline \multicolumn{2}{|c|}{$\begin{array}{c}\text { Range of } \\
\text { One Category }\end{array}$} & \multicolumn{2}{|c|}{$\begin{array}{c}\text { Range of } \\
\text { Two Categories }\end{array}$} & \multicolumn{2}{|c|}{$\begin{array}{c}\text { Range of } \\
\text { Three Categories }\end{array}$} \\
\hline $\begin{array}{l}\text { Extreme } \\
\text { Opinions }\end{array}$ & $\begin{array}{c}\text { No. of } \\
\text { Films }\end{array}$ & $\begin{array}{l}\text { Extreme } \\
\text { Opinions }\end{array}$ & $\begin{array}{l}\text { No. of } \\
\text { Films }\end{array}$ & $\begin{array}{l}\text { Extreme } \\
\text { Opinions }\end{array}$ & $\begin{array}{l}\text { No. of } \\
\text { Films }\end{array}$ \\
\hline $\begin{array}{l}\text { Absent-slight } \\
\text { Slight- } \\
\text { moderate } \\
\text { Moderate- } \\
\text { marked .. }\end{array}$ & $\begin{array}{l}6 \\
7\end{array}$ & $\begin{array}{c}\text { Absent- } \\
\text { moderate } \\
\text { Slight- } \\
\text { marked } \\
-\end{array}$ & $\begin{array}{l}2 \\
4\end{array}$ & $\begin{array}{c}\begin{array}{c}\text { Absent to } \\
\text { marked }\end{array} \\
-\end{array}$ & 2 \\
\hline Totals $\ldots$ & 19 & & 6 & & 2 \\
\hline
\end{tabular}


the extremes of the range of mottling recorded. It can be seen that in two films there was such marked disagreement that the same film would be placed in any of the four categories according to the observer viewing the film. In six more there was a range of opinion of two categories.

Second Occasion (Observers $F$ to $K$ ). - The films were considered as a whole and the severity of mottling assessed according to the individual observer's own criteria of slight, moderate, or marked change. It was decided not to use standard films on this occasion since they are not at present used routinely by the pneumoconiosis medical boards. The frequency with which mottling was recorded and the number in each grade are shown in Fig. 6. The number of films thought to show mottling varied from 21 to 33 . Although this gives some idea of the disagreement between the observers it does not show the whole picture. There was in fact complete agreement on the severity of mottling in three films only. In the others the range of mottling observed is shown in Table III, where the films have been grouped according to the extremes of the range of opinion

TABLE III

RANGE OF EXTREME OPINIONS OF OBSERVERS F-K IN 35 FILMS WITH DISAGREEMENT ON GRADE OF MOTTLING

\begin{tabular}{|c|c|c|c|c|c|}
\hline \multicolumn{2}{|c|}{$\begin{array}{c}\text { Range of } \\
\text { One Category }\end{array}$} & \multicolumn{2}{|c|}{$\begin{array}{c}\text { Range of } \\
\text { Two Categories }\end{array}$} & \multicolumn{2}{|c|}{$\begin{array}{c}\text { Range of } \\
\text { Three Categories }\end{array}$} \\
\hline $\begin{array}{l}\text { Extreme } \\
\text { Opinions }\end{array}$ & $\left|\begin{array}{c}\text { No. of } \\
\text { Films }\end{array}\right|$ & $\begin{array}{l}\text { Extreme } \\
\text { Opinions }\end{array}$ & $\mid \begin{array}{c}\text { No. of } \\
\text { Films }\end{array}$ & $\begin{array}{l}\text { Extreme } \\
\text { Opinions }\end{array}$ & $\begin{array}{l}\text { No. of } \\
\text { Films }\end{array}$ \\
\hline $\begin{array}{l}\text { Absent-slight } \\
\text { Slight- } \\
\text { moderate } \\
\text { Moderate- } \\
\text { marked .. }\end{array}$ & $\begin{array}{l}5 \\
3\end{array}$ & $\begin{array}{c}\text { Absent- } \\
\text { moderate } \\
\text { Slight- } \\
\text { marked } \\
-\end{array}$ & $\begin{array}{l}9 \\
1\end{array}$ & $\begin{array}{c}\text { Absent to } \\
\text { marked } \\
-\end{array}$ & 7 \\
\hline Totals $\ldots$ & 18 & & 10 & & 7 \\
\hline
\end{tabular}

recorded. It is to be noted that in addition to the 28 cases in which the range of opinion was one or two categories there were seven with a range of three categories, i.e., the opinions recorded in these seven films varied from no mottling to marked mottling according to the observer.

Shaggy Heart, Pleural Reaction, and BULlaE.-There was considerable disagreement between the observers on the presence or absence of these signs. Some idea of this can be obtained by comparing the number of films in which the sign is recorded as present by one or more observer with the number in which it was found to be present by the majority, i.e., six or more. This is shown in Table IV. Although a shaggy border to the heart was recorded as present by
TABLE IV

DISAGREEMENT BETWEEN OBSERVERS IN DIAGNOSIS OF SHAGGY HEART APPEARANCES, PLEURAL REACTION, AND BULLAE

\begin{tabular}{|c|c|c|c|}
\hline & $\begin{array}{c}\text { Shaggy } \\
\text { Heart }\end{array}$ & $\begin{array}{c}\text { Pleural } \\
\text { Reaction }\end{array}$ & Bullae \\
\hline $\begin{array}{l}\text { Recorded as present by one or } \\
\text { more observers } \\
\begin{array}{l}\text { Recorded as present by six } \\
\text { more observers }\end{array} \text {.. }\end{array}$ & $\begin{array}{r}25 \\
3\end{array}$ & $\begin{array}{l}29 \\
15\end{array}$ & $\begin{array}{r}30 \\
6\end{array}$ \\
\hline
\end{tabular}

one or other of the observers in 25 of the 38 patients who had been exposed to asbestos, in only three of these did the majority agree on its presence. Similarly there was marked disagreement on the presence or absence of bullae but better agreement with pleural reaction.

\section{Discussion}

There were several surprising findings in this study. One was the extent of the disagreement between the observers in the diagnosis of the films from the certified cases of asbestosis. These patients had all been seen and certified by the pneumoconiosis medical panels and had initially been selected by us as classical examples of the disease. Yet when the same films were viewed in the present trial the number thought to show changes consistent with the diagnosis of asbestosis varied from 40 to $80 \%$ approximately according to the observer. This study might be criticized on the grounds that if the industrial history or physical signs of these patients had been known many of the films regarded as abnormal but not asbestosis would have been correctly diagnosed. Nevertheless it was emphasized at the beginning on both occasions that the decision was not whether the patient did or did not have asbestosis but whether the changes seen in the radiographs were consistent with this diagnosis. It is clear also that the discrepancy of opinion was not due to poor selection of observers, as they all had special experience in this field and with one exception had little difficulty in diagnosing the films from the normal subjects.

The difficulties in the diagnosis of the early radiological changes of asbestosis have been emphasized repeatedly by Pendergrass since 1938, so that it was not surprising to find a difference of opinion in the diagnosis of the films from the group of patients who had been exposed but in whom previously the radiographs had been regarded as clear. However, the extent of this disagreement was quite remarkable and it is clear that little reliance can be placed on the presence of radiological changes in the diagnosis of early 
cases. Sander (1955) came to the same conclusion. He describes a formal trial held by the air hygiene committee of the asbestos textile industry in America in which sample films of asbestosis of varying stages, including some essentially normal, were reviewed by eight experienced physicians. They found that there was no agreement on the borderline cases and that it was impossible to define a first-stage case as the same film would be called "essentially normal " one day and "first stage" the next day by the same observer.

It is impossible to draw any firm conclusions regarding the value of standard films which were used with the first group of observers, as the experiment was not repeated in the absence of such films. Certainly there is considerable observer variation even with their use, and it is difficult to believe that they were of much value in the diagnosis of borderline cases. It does seem, however, that with them a meaningful grading of radiological change was obtained, for there was a highly significant correlation $(r=-0.74, P$ $<0.001$ ) between the grade of radiological mottling and the degree of reduction in diffusing capacity (Williams and Hugh-Jones, 1960). Fletcher and Oldham (1951) found with similar problems in coalworkers' pneumoconiosis that the use of standards enabled some but not all of the observers to achieve a greater accuracy and consistency in classification. The least experienced observers benefited most, though they tended to make false diagnoses of abnormality in normal films when working with standards, whereas the more experienced observers found them of greater help in the discrimination of normal films from those with slight abnormality than in the classification of abnormal films. There is no doubt that there was much greater disagreement with the second group of observers in the assessment of radiological mottling. It is not justifiable to compare the findings on the two occasions, for they were by different groups of observers, and it is impossible to assess the standards of abnormality by which the films were judged on the second occasion.

It is clear that the other radiological signs of asbestosis, such as the shaggy heart appearance and pleural reaction, are also subject to considerable observer variation. It was of interest to find that bullae, which are not usually regarded as one of the classical features of the radiological changes in asbestosis, were present rather more frequently than the shaggy heart appearance. It is important to realize that differences in disagree-

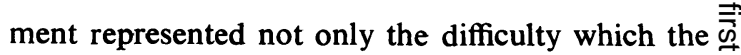
observers found in detecting the various signs but $\bar{C}$ also reflect the degree to which these signs were $\bar{D}$ positive. For instance, the high level of disagree- $\frac{\bar{s}}{\frac{\sigma}{2}}$ ment in deciding on the presence or absence of $a \stackrel{\otimes}{\triangle}$ shaggy heart or bullae may in part be due to the fact that this group of films did not show these signs to a marked degree. On the other hand, it. may be equally due to the fact that the observers $\overrightarrow{\vec{J}}$ found these signs particularly difficult to interpret. In the absence of any absolute opinion as to the $\overrightarrow{\vec{x}}$ presence or absence of a particular change, it is $\overrightarrow{\vec{r}}$ impossible to separate these two influences.

In conclusion it is apparent, from the observers? findings in the group of films from other pul- $\stackrel{\omega}{\circ}$ monary diseases, that the radiological appearances 0 in asbestosis are by no means specific, and may be confused with such widely differing diseases as $\subset$ chronic bronchitis and emphysema, sarcoidosis, and other pneumoconioses. Presumably if other inter- $\vec{D}$ stitial fibroses such as scleroderma, lymphangitis $\mathscr{O}$ carcinomatosa, xanthomatosis, or beryllium. granuloma had been included in this group the confusion would have been even greater.

\section{SUMMARY}

A trial was held to see if the radiological $\stackrel{2}{\Rightarrow}$ changes in asbestosis were specific and to what extent their diagnosis and grading were affected by observer variation.

Eleven experienced observers were asked to read independently a series of 53 radiographs which contained examples of asbestosis, other pulmonary fibroses, and films from normal $\stackrel{0}{\circ}$ subjects.

The results showed that the radiological $\delta$ appearances of asbestosis were quite unspecific 3 except in some advanced cases and observer 0 variability in grading asbestosis was great.

The use of standard films both in the diagnosis and grading of the radiological changes needs further trial.

We should like to thank the observers who took part in the trial, Dr. C. M. Fletcher for his constant 0 interest and advice, and Dr. J. C. McVittie, of the Ministry of Pensions and National Insurance, for his help in organizing the second part of the study.

\section{REFERENCES}

Fletcher, C. M., and Oldham, P. D. (1951). Brit. J. industr. Med., 8,

International Labour Organization (1959). Occup. Safety Hlth, 9, 63. Pendergrass, E. P. (1938). In Silicosis and Asbestosis, ed. Lanza, A. J., p. 174. Oxford University Press, London.

Sander, O. A. (1955). A.M.A. Arch. industr. Hlth, 11, 208.

Williams, R., and Hugh-Jones, P. (1960). Thorax, 15, 109. 